\title{
CÁTEDRAS PARALELAS: INTERTEXTUALIDAD E INCORPORACIÓN DEL ESPAÑOL DE CHILE
}

\author{
CÁTEDRAS PARALELAS: INTERTEXTUALITY \\ AND INTEGRATION OF CHILEAN SPANISH
}

\author{
Magdalena Vigneaux \\ Universidad de Chile. Santiago, Chile \\ msvignea@uc.cl
}

\begin{abstract}
$\mathrm{E}$ N 2015 Se cumplieron 30 años desde la publicación de Cátedras paralelas (1985) y, a pesar de que han pasado 25 desde el retorno a la democracia, la situación de la cultura y el funcionamiento del mundo universitario descritos en esta novela siguen estando de algún modo vigentes. Si bien es cierto que ya no se está dentro de un régimen de interdicción y el intelectual cuenta con mayor libertad de expresión, se continúa dentro de una sociedad en la que los valores mercantiles se superponen a los valores culturales y espirituales. Además, la novela sigue siendo muy actual al mostrar lo que en términos foucaultianos se denomina la diseminación del poder, pues nunca está suficientemente claro quién decide el despido de Rojitas.
\end{abstract}

Ahora bien, en este trabajo no se pretende demostrar la actualidad de esta novela a nivel de contenido ni detenerse en la crítica a las condiciones de existencia bajo la dictadura que la novela reviste, sino centrarse en algo más próximo a la contemporaneidad de sus procedimientos literarios y, más específicamente, en cómo Andrés Gallardo dialoga con la tradición literaria e incorpora el español de Chile a su texto. En este sentido, se revisará el diálogo que se establece con los dos principales intertextos de la literatura nacional presentes en la novela, a saber: Zurzulita (1920) de Mariano Latorre y Alsino (1920) de Pedro Prado.

En el artículo "Dos formas de recuperación de la oralidad de la narrativa chilena" (2011), Gallardo analiza, precisamente, cómo Zurzulita y Alsino 
constituyen los primeros intentos por integrar la realidad lingüística nacional al texto literario, aunque lo hacen de manera diferente. Mientras Mariano Latorre recoge textualmente el coloquio popular chileno y establece una separación entre su propia voz y la de los personajes, Pedro Prado inserta el habla de los personajes rurales a través de una evocación dentro de su mismo discurso, sin la separación tajante que existe en el caso de Latorre. Sin embargo, aunque Gallardo reconoce un valor en el trabajo de estos escritores, sostiene que ninguno de los dos logra incorporar "con plenitud, con desparpajo y con seguridad, la realidad de la propia lengua" (26).

Si bien el artículo antes mencionado es bastante posterior a la escritura de Cátedras paralelas, es probable que en la elaboración de esta novela Gallardo ya hubiera pensado algunas de las ideas que ulteriormente desarrollara. Así, es posible leer Cátedras paralelas como una propuesta de incorporación del español de Chile, que ni la novela de Mariano Latorre ni la de Pedro Prado habría logrado con plenitud. O bien, dicho de otro modo, como una forma de alcanzar en el ámbito de la narrativa lo que en poesía ya había conseguido con ejemplaridad Nicanor Parra, es decir, la incorporación del coloquio popular chileno al texto literario.

A diferencia de lo que ocurre en Zurzulita y Alsino, en Cátedras paralelas el español de Chile se inserta como un castellano no marcado, en el sentido de que el léxico chileno se legitima como lenguaje literario y no es solo recogido por un autor que asume la norma española estandarizada. Si bien esto se logra parcialmente en Alsino, donde no existe una escisión entre el lenguaje del autor y el de los personajes tan rotunda como en la novela de Latorre, Prado también parece atenerse a una norma codificada según la retórica tradicional española, como se evidencia en que "en los momentos más líricos de los cantos predomina el uso de 'vosotros', inexistente en el coloquio chileno, aun en el coloquio culto" (Gallardo, 2011: 26). En cambio, en Andrés Gallardo la lengua chilena sí parece alcanzar el arraigo ${ }^{1}$ suficiente como para integrarse sin marca dentro del texto literario.

${ }^{1} \mathrm{El}$ arraigo, según el mismo Gallardo, es una de las propiedades culturales del idioma estándar. "La propiedad cultural del arraigo implica que el idioma estándar está ligado al acervo histórico de la comunidad hablante en cuanto sociedad culturalmente identificable" (1978: 91). Sin embargo, no se trata de una propiedad diacrónica, sino sincrónica, pues un idioma es arraigado por su relación con una tradición cultural viva. En este sentido, un alto grado de arraigo favorece el cultivo de las actividades intelectuales y culturales del idioma estándar. 
En Cátedras paralelas hay un narrador básico cuyo uso frecuente del estilo indirecto libre y su apego a la conciencia de Rojitas demuestra que hay un intento por eliminar las jerarquías entre su habla y el de los personajes. Si bien en algunos momentos de la novela se produce una distancia entre el personaje y el narrador, esta no se establece para mostrar la superioridad en el uso idiomático de este último, sino para establecer una superioridad en términos de conciencia: la superioridad del narrador lúcido, que ve lo que está pasando, sobre el personaje ingenuo. Esta es la ironía clásica de la novela, cuyo modelo por antonomasia es quizás El Quijote, el que, por lo demás, es un intertexto de la literatura universal importantísimo en el texto de Gallardo.

La novela de Gallardo arranca con la imagen del sobre azul, que Mauricio Ostria describe como un motivo con características expresionistas y que, sin duda, es profundamente literaria. Así, esta expresión empleada en Chile para referirse al sobre que contiene la notificación del despido laboral se presenta como tan válida culturalmente que puede ser usada por el narrador sin ningún aparato introductorio o explicativo. El sobre azul no solo tiene valor por su función como desencadenante del conflicto y por ser un símbolo del poder, sino también por darle categoría literaria a un uso propiamente chileno. La literariedad del motivo del sobre se refleja perfectamente en el paso de este de la pasividad a un rol de agente, muy bien descrito por Ostria en el artículo que epiloga la novela.

Los diminutivos, característicos del español de Chile, son fundamentales dentro del aspecto discursivo de la novela. En efecto, los diminutivos están sumamente presentes en el texto: 'calientito' (9), 'un besito cortito no más' (9), 'tomaditos de la mano no más' (10), 'ropita' (17), 'calzoncito' (55), 'sostencito' (55), 'enagüita' (55), 'cerquita' (71), 'patitas' (71), 'despacito’ (71), 'tempranito' (72, 94), 'suavecitos' (72), 'hoyitos' (72), 'tecito' $(76,77)$, 'papelito' (77), 'tosecita' (87), 'frasecita' (90), 'autito' (95, 96), 'solitos' (98), 'viejito' (99), ‘el auto es una joyita' (99), 'vestidito' (101) y, por supuesto, 'Rojitas'. Estos no solo son usados por el narrador con completa naturalidad, sino que también sirven al tono menor del relato y a la minimización de los personajes y acontecimientos ${ }^{2}$.

\footnotetext{
${ }^{2}$ Para comprender la minimización como parte de una 'estética del guiño' presente en la novela, véase el artículo de Mauricio Ostria (1985).
} 
Otros chilenismos ${ }^{3}$ presentes en Cátedras paralelas son los provenientes del ámbito culinario. Por ejemplo, se hace referencia al 'lomito' (29), al 'chacarero' (53), a los 'picorocos' (30), al 'charquicán' (60), al 'piure' (98), al 'ulte' (98) y al 'pipeño' (98). De hecho, Miguel, uno de los amigos de Rojitas que está en el exilio, anhela comer un lomito. En este sentido, los chilenismos tienen una función dentro del relato, que en este caso es la de enfatizar la nostalgia por la patria. También permiten construir una literatura "situada", que alude a un lugar y un tiempo específicos, y que en la novela es el Chile de los años ochenta. Una expresión que, además de tener una marca geográfica, da clara cuenta de que se trata de los ochenta es la palabra 'dije' (89), que hoy está quedando en desuso. Además, es relevante que esta palabra sea empleada por Marta, la madre de Rosario Lamas Pérez-Cotapos, pues es un término que también tiene una marca de clase.

Expresiones como 'está de lo más bien' (62), 'me está pichuleando' (81) o 'mostrar la hilacha' (94) son usos coloquiales propios de lengua chilena que la novela integra sin darles ningún trato peyorativo, sino como frases dignas de hacerse parte del discurso literario. También se incorporan indigenismos como 'chupalla' (47), 'huachis' (50), 'quiltro' (52), 'pilme' (59), 'charquicán' y 'trutros' (20)4. Esta última palabra se ocupa en su acepción coloquial, para referirse a los muslos de la Antonieta y la Guillermina. Todos estos términos son integrados como un castellano no marcado, es decir, sin estigmatizarlos socialmente.

Se ha reservado para el final la mención de aquellos chilenismos que remiten a la flora y fauna nacionales, pues, además de la abundancia de referencias -sobre todo en el caso de la flora-, permite introducir el tratamiento del diálogo que Cátedras paralelas establece con el criollismo. En efecto, en la novela criollista el entorno natural adquiere un protagonismo indiscutible, tanto que la trama se transforma solo en un pretexto para escenificar las costumbres campesinas. En la novela de Gallardo, no

${ }^{3}$ Por chilenismos se entiende aquellos usos idiomáticos específicos del español de Chile, es decir, aquellas expresiones y palabras que son propias de los chilenos, aunque no necesariamente exclusivas, pues pueden ser compartidas por otros hablantes de lengua castellana, pero nunca por todos ellos.

${ }^{4}$ Para el significado de estas palabras y de la mayoría de los chilenismos que este artículo recoge, puede consultarse el Diccionario de uso del español de Chile (DUECh), en cuya elaboración Andrés Gallardo participó como parte de la comisión lexicográfica. 
son pocos los momentos en que se describe el paisaje ni son pocas las referencias a especies animales y vegetales, como se ejemplifica claramente en el episodio en que Rojitas va a dejar la chacra La Gloria para volver a su trabajo como profesor de teoría literaria:

[...] quizás algún día [La Gloria] hasta podría volver a ser alegría veraniega, quizás, claro, hasta hablaría y además de álamos y sauces cantarían en coro claramente discernible arrayanes, pataguas, quillayes, boldos, espinos, maquis, peumos, litres, quiscos, algarrobos, entonces, sin duda, por las mañanas cantarían de modo claramente discernible diucas, chercanes, chincoles, cuculíes, zorzales, loicas, guairavos, tordos, pitíos, además de las gallinas escuálidas que picoteaban por todos lados y de las moscas [...] (94-95).

El criollismo ${ }^{5}$ entra en la novela por medio de una relación intertextual. Aunque hay citas textuales de Luis Durand y Oscar Castro ${ }^{6}$, el intertexto fundamental es Zurzulita, de la que no solo aparecen fragmentos, sino que también forma parte de la construcción del discurso y de la trama. Además de las citas de fragmentos de esta novela, hay una referencia bastante directa en que Rojitas use el apodo 'Zurzulita' para llamar a Sandra MárquezLagunas, de quien dice que es "fea como un loro". Así, se muestra la relación abiertamente paródica que Gallardo instaura con el texto de Latorre, pues Milla, la atractiva 'preceptorcita' de Latorre, es reemplaza por Sandra, la desolada profesora 'cara de loro'. Asimismo, que Rojitas hable de "la más tersa narrativa” (78) para referirse a la narrativa criolllista no puede más que mover a risa al lector, quien lo contrasta con los intrincados fragmentos que enseguida el protagonista lee a don Venancio.

A nivel de argumento, existen algunas similitudes entre Zurzulita y Cátedras paralelas. Si en la novela de Latorre la muerte del padre de Mateo

${ }^{5}$ En "El criollismo en Chile", Dieter Oelker (1983) señala: "Podemos distinguir, en la crítica literaria chilena, dos usos de la palabra criollista y criollismo: uno en sentido restringido, como 'la creación novelesca que se refiere a las costumbres y a la vida del pueblo en el campo' (Luis Durand, 1947) y que es, sin duda, el que prevalece, y en otro sentido amplio (y programático), como 'la pintura del hombre de América y de sus costumbres, clases bajes, medias y altas, de ciudades y campos' (Mariano Latorre, 1953)”.

${ }^{6}$ En la novela, Rojitas lee a don Venancio los cuentos “Afuerinos”, de Luis Durand, y “El último disparo del negro Chaves", de Óscar Castro. 
Elorduy motiva el traslado de este último al campo, en Cátedras paralelas el despido laboral da inicio al desplazamiento de Rojitas desde la ciudad provinciana a la capital y de esta a la chacra. Aunque gran parte de la novela de Gallardo transcurre dentro del escenario urbano, es necesario el espacio de Riconada de Tromén para generar el vínculo con la narrativa criollista, a pesar de que, en su acepción más amplia, el criollismo retrata la vida del hombre de América, tanto del ámbito urbano como del rural'7. El tiempo que se abarca en ambas novelas está en directa relación con la salida de los protagonistas de sus respectivos pueblos. Zurzulita comprende el lapso de un año aproximadamente, desde la salida de Mateo hasta su frustrado regreso a Loncomilla: "Aquel año campesino era como un lejano cautiverio, lejos de la civilización y del mundo, del cual iba a libertarse muy pronto. Volvería a Loncomilla y a su vida antigua de la cual no debió salir" (311). El tiempo de Cátedras paralelas está enmarcado por el despido y la reincorporación de Rojitas a su trabajo como profesor de teoría literaria y, aunque no se especifica cuánto tiempo transcurre, es perfectamente admisible que se trate de un año. No obstante, en el texto de Gallardo el regreso ocurre efectivamente, mientras que en el de Latorre se ve malogrado por la muerte de Mateo.

Cátedras paralelas contiene algunas referencias explícitas a la novela criollista: "[Rojitas] tenía vagos recuerdos mayormente veraniegos [de la chacra] fomentados por fotos descascaradas o por alguna página de novela criollista [...]" (43), "[...] el fantasma metete se contenta con los recuerdos criollistas de Rinconada de Tromén [...]" (51-52), "No. Ni en una novela criollista ni en una telenovela podía pasar una cosa así" (66). Estas referencias ponen en "evidencia al criollismo como una serie textual, lo alude y al hacerlo, deja al descubierto su carácter de letra, de signo, de ficción" (Ostria 114). Los novelas criollistas parecen constituir lecturas de la infancia que están cargadas con cierta añoranza del tiempo en que Rojitas veraneaba con su abuela en la ese entonces gloriosa Rinconada de Tromén. Por lo tanto, además de la relación paródica con la novela criollista, hay una especie de vínculo sentimental, pues al fin y al cabo en Gallardo también hay un reconocimiento de Latorre como maestro del criollismo chileno.

${ }^{7}$ Vuélvase a la nota 5 de este artículo, específicamente a la definición dada por Latorre a criollismo. 
La literatura criollista tiene un carácter épico totalmente ausente en Cátedras paralelas. La novela criollista escenifica la lucha entre el hombre y la naturaleza, "[y] este aspecto de inmediata lucha con el medio, siempre hostil (soledad, frío, hambre) es lo que da a este tipo de hombre un carácter original, primitivo, épico” (Latorre, 1953: 81). En Cátedras paralelas, esta lucha no existe ni hay ningún tipo de heroicidad en el protagonista. Al contrario, Rojitas es un antihéroe, lo que se evidencia ya en la misma diminutivización de su apellido. Rojas Cruchaga se conforma con su puesto de profesor de teoría literaria: no aspira a subir su rango académico y menos a generar cambios sociales. El despido mismo es producto de una mala lectura de su artículo y no de que este último realmente contenga ideas revolucionarias o antisistémicas. De hecho, a mediados de los ochenta, en que probablemente se sitúa la historia, los hombres transgresores ya estaban muertos o en el exilio.

La lucha retratada en la novela criollista, además, tiene un carácter trágico, pues el hombre termina siendo vencido por la naturaleza. En cambio, en la novela de Gallardo el final es antitrágico, ya que el protagonista no muere ni mucho menos, sino que se produce una especie de retorno al punto de partida: Rojitas vuelve a ejercer su cargo de profesor en la universidad de provincia y el tiempo fuera de las aulas pasa a ser solo una "temporada en el fundo" (102). Este final también se caracteriza por ser inesperado, a diferencia de lo que ocurre en la narrativa criollista, en la que los sucesos se organizan causalmente hasta el desenlace fatal. Cátedras paralelas no sigue esta lógica causal, sino que muestra la manera más o menos azarosa como funcionan las cosas en la realidad.

Como se puede desprender a partir de lo que se ha dicho sobre la importancia de la naturaleza en los textos criollistas, la explicitación de los contextos espaciales y sociales es fundamental en la literatura de este tipo, mientras que en Cátedras paralelas generalmente se eluden las referencias a contextos político-sociales. Por la única vía en que se sabe directamente que los acontecimientos relatados suceden bajo un régimen dictatorial es a través de las cartas que los amigos de Rojitas envían desde el exilio y que se intercalan en la narración. Esta elusión es una manera de dar una apariencia inofensiva a una novela que contiene una fuerte crítica a la dictadura y a la sociedad. A esta apariencia contribuye también el sentido del humor que impregna toda la novela, completamente opuesta a la seriedad de una novela como Zurzulita. 
Ya que la narrativa criollista es parodiada y actúa como intertexto de la novela, es un error hablar de Gallardo como un escritor criollista sin más. En este sentido, son más apropiados los términos de neocriollismo, propuesto por Ostria, o postcriollismo, utilizado por Cánovas. Ambos vocablos intentan recoger la contemporaneidad de la obra de Gallardo, no solo en el sentido de su posterioridad cronológica, sino en el de su incorporación de las técnicas narrativas contemporáneas. Rodrigo Cánovas parece ver que a través del uso de la parodia se logra una superación del criollismo de los años veinte:

El relato de Andrés Gallardo recupera el espacio mental acotado por el criollismo, desde su parodia (sentimental y lúdica). El criollismo de los años 20 encuentra su réplica en una novela postcriollista del año 1987, que renueva la tradición del género (es decir, reformula el contrato mimético original), a la luz de los postulados de la lingüística moderna (107).

Si bien esta cita se refiere a La nueva provincia, es perfectamente extrapolable a Cátedras paralelas, pues en esta última es precisamente una renovación del género criollista lo que se encuentra. Es una renovación porque en la novela de Gallardo sí hay una respuesta al llamado de Mariano Latorre de hacer propios los temas de Chile ${ }^{8}$.

Respecto de la intertextualidad con Alsino, esta se refleja principalmente en dos pasajes. El primero es el momento en que el protagonista sueña que vuela: "Durante varias noches a Rojitas le dio con soñar que volaba sobre Rinconada de Tromén con unas alas enormes" (70). Y Alsino es, justamente, el niño que sueña que vuela:

${ }^{8}$ En Algunas preguntas que no me han hecho sobre el criollismo, Mariano Latorre escribe: "Y éste es el llamado a las jóvenes generaciones: renunciar a lo extranjero, hacer propios, con la técnica de los países más viejos o más evolucionados, los temas de Chile" (1953: 75). Si bien Andrés Gallardo acoge este llamado en el punto de hacerse cargo de los temas chilenos, hay cierta discrepancia en que deba asumirse la técnica de los países más viejos, al menos en lo que se refiere al hecho de que el autor deba asumir la norma estándar. Gallardo, además, aunque se haga cargo de temas de Chile, mantiene un diálogo con la literatura universal y con lo extranjero. 
Sueña que volar es una hazaña que no requiere esfuerzo alguno; sueña que volar es un hecho fácil para todo aquel que deje su peso en tierra. Se asombra de no haber tenido antes tal ocurrencia, y una y otra vez, sólo con la fuerza de su propia voluntad, se desprende suavemente del suelo, poco a poco se eleva, y va y viene, con rapidez, por el aire (Prado, 1975: 10).

Soñar que se vuela despierta en Alsino ansias por volar, mientras que en Rojitas suscita un sentimiento de vergüenza, quizás porque en el protagonista de Cátedras paralelas no está el deseo de elevarse por encima del mundo visible, sino que sus intereses son sumamente terrenales, pues las alas le podrían ser útiles para identificar dónde la tierra produciría y le traería rentas: “[...] después de todo, no estaría de más tener un buen par de alas para elevarse a recitar himnos a la chacra, a ver si mostraba el lado por donde había de florecer" (70). Si el sueño de Alsino es anticipatorio de las alas que posteriormente le saldrán y de las alturas que alcanzará con ellas, el sueño de Rojitas es un indicio de sus pobres aspiraciones.

El segundo episodio es el del paisaje que Rojitas mira desde el tren que lo lleva de vuelta a la ciudad provinciana: "El ritmo del tren ayuda a que los otros recuerdos se vayan pareando con los campos cada vez más verdes, con los pueblos de casas cada vez más grises, con los pinos que quieren cubrir toda la tierra, con los ríos cada vez más frecuentes” (97). El desfile de imágenes que se va sucediendo en el tren se asemeja a la vista que tiene Alsino de las ciudades desde lo alto: "Todo desfila en rápida sucesión. ¡Cuán poco tiempo, mientras vuelo, está bajo mi vista una ciudad!” (Prado, 1975: 72).

Las relaciones intertextuales y la manera de incorporar el español de Chile que se han descrito en este artículo permiten dar cuenta de la contemporaneidad de la obra de Andrés Gallardo. Esta contemporaneidad también se refleja en el uso de otros recursos literarios como la discontinuidad (intercalación de informaciones ajenas a la narración principal), la fragmentación (numeración no secuencial de los capítulosª), la perspectiva

9 Tuve la oportunidad de comunicarme con Andrés Gallardo, quien me indicó que la numeración se debía, precisamente, a un intento por mostrar la fragmentariedad de los acontecimientos y que el hecho de que haya un capítulo 6.9 intensifica su rasgo tan frag- 
variable (apego y distanciamiento de la conciencia de Rojitas), la pluralidad de voces (la de Rojitas, la de los amigos en el exilio, la de los "murmullos" ${ }^{\text {"10 }}$ la de Rosario, entre otras), la diversidad de registros de habla (culto e inculto, formal e informal). Si bien el tratamiento en profundidad de cada uno de estos elementos supera el alcance de este trabajo, es importante hacer la mención de ellos para comprender por qué Gallardo no puede entenderse simplemente como un escritor criollista.

Para finalizar, es necesario recordar que Andrés Gallardo, fallecido el presente año, era doctor en Lingüística, pues no puede pasar desapercibido que su trabajo como lingüista y como literato están íntimamente relacionados. En efecto, su interés por los usos idiomáticos chilenos no solo se refleja en su producción literaria, sino también en su trabajo en la Academia Chilena de la Lengua y, específicamente, en su participación en la elaboración del Diccionario de uso del español de Chile (DUECh), como parte de la comisión lexicográfica. También se interesó por el estudio de las relaciones entre oralidad y escritura y de los procesos de estandarización de la lengua, que, sin duda, están inmersos en su producción narrativa.

\section{Referencias}

Cánovas, R. (1991). Una reflexión sobre la novelística chilena de los años 80. Revista Chilena de Literatura, 38, 101-110.

Gallardo, A. (1978). Hacia una teoría del idioma estándar. RLA, Revista de Lingüistica Teórica y Aplicada, 16, 85-117.

. (1985). Cátedras paralelas. Concepción: LAR.

. (2011). Dos formas de incorporación de la oralidad en la narrativa chilena. Anales de la Literatura Chilena, 15, 13-27.

$\overline{\text { mentario como marginal. Además, destacó que otro rasgo de tenerse cuenta es el capítulo }}$ que va enmarcado, cuya idea original era que se tratara de la imagen de un espejo en el cual se miraba, complacida, Rosario Lamas, sin embargo, la imprenta era muy precaria para dibujar el marco labrado del espejo. En este sentido, es interesante cómo las condiciones materiales y técnicas también tienen incidencia en el resultado final de un texto.

${ }^{10}$ Es posible hablar de una "retórica de murmuración" presente en la novela. Esta retórica queda en evidencia en el "dicen que" que da inicio a los capítulos 1.5 y 6.5 -que abandonan la perspectiva del protagonista para informar acerca de las gestiones de doña Marta para enterarse del porqué del despido de Juan Pablo y para conseguir su reincorporación, respectivamente. 
Latorre, M. (1952). Zurzulita. Santiago: Nascimento. (1953). Algunas preguntas que no me han hecho sobre el criollismo. Santiago: Ediciones de los Anales de la Universidad de Chile.

Oelker, D. (1983). El criollismo en Chile. Acta Literaria, 8, 37-51.

Ostria, M. (1985). Cátedras paralelas: Neocriollismo, intertextualidad y la despiadada verdad histórica, epílogo a Cátedras paralelas. Concepción: Lar. Prado, P. (1975). Alsino. Santiago: Nascimento. 